\section{Plasma endothelin-1 immunoreactivity is increased following long-term dietary supplementation with $\omega-3$ fatty acids in microalbuminuric IDDM patients}

Dear Sir,

Circulatory concentrations of plasma endothelin-1 (ET-1), an endogenous vasoactive peptide, are increased in diabetes mellitus. Raised ET-1 levels have been proposed as a marker of endothelial dysfunction in this disease $[1,2]$. We hypothesize that ET-1 changes could be associated with the endothelial/rheological effects of supplements of $\omega-3$ fatty acids $(\omega-3$ FAs), a dietary intervention advocated in diabetes [3].

We measured plasma ET-1 immunoreactivity in 18 microalbuminuric IDDM patients (urinary albumin excretion rate $30-300 \mathrm{mg} / 24 \mathrm{~h}$ in at least two of three consecutive urinary collections), who were treated for 9 months, according to a double-blind schedule, with either $2.4 \mathrm{~g} /$ day $\omega-3$ FAs $(84 \%$ eicosapentaenoic, $16 \%$ docosahexaenoic acids; gift of Sanofi, Brussels, Belgium; $n=8)$ or an inert placebo $(n=10)$. Patients in the two groups were comparable for age, sex, duration and complications of diabetes, insulin requirements, $\mathrm{HbA}_{1 \mathrm{c}}$, body mass index and waist-hip ratio. We also measured plasma ET1 in a group of normoalbuminuric IDDM patients $(n=23)$ as control. Plasma was obtained from venous blood taken into $9 \mathrm{mmol} / \mathrm{l}$ benzamidine and $3 \mathrm{mmol} / \mathrm{l} \mathrm{EDTA}$, and stored at $-80^{\circ} \mathrm{C}$. ET-1 immunoreactivity was measured as previously described [4], after extraction on $\mathrm{C}_{18}$-Sep Pack (Millipore, Mil ford, Mass., USA), using commercial antibody and standard (Peninsula Labs, Belmont, Calif,, USA).

As previously reported [5], ET-1 immunoreactivity was higher in microalbuminuric than in normoalbuminuric patients $(1.9 \pm 0.2$ vs $1.5 \pm 0.2 \mathrm{pmol} / \mathrm{l}$, mean $\pm \mathrm{SEM}, n=10$ and 23 , $p<0.05$, Mann-Whitney's test). ET-1 immunoreactivity was further increased in $\omega-3$ FAs-supplemented microalbuminuric diabetic patients compared with those receiving placebo $(2.4 \pm 0.1$ vs $1.9 \pm 0.2 \mathrm{pmol} / 1$, mean $\pm \mathrm{SEM}, n=8$ and $10, p<0.05)$. ET-1 immunoreactivity was further characterized in one non-microalbuminuric, two placebo-treated microalbuminuric, and three $\omega-3$ FAs-supplemented microalbuminuric diabetic patients by reverse phase HPLC (24-44\% acetonitrile gradient on a $\mathrm{C}_{18}$ TSKODS-120 T column, Toso Haas, Germany) (Fig. 1). ET1 immunoreactivity eluted similarly to synthetic ET-1 (Peninsula), appearing as two peaks, corresponding to oxidized-ET-1 and to the intact peptide (ET-1). Weak immunoreactivity was also detected close to the elution position of synthetic big ET-1. In contrast to ET-1, the immunoreactivity of plasma angiotensin II, another vasoconstrictor peptide, was similar in $\omega-3$ FAsand placebo-supplemented patients $(12.6 \pm 1.8$ vs $14.6 \pm$ $1.9 \mathrm{pmol} / 1, n=8$ and 10 ).

In conclusion, ET-1 plasma immunoreactivity is increased following long-term dietary supplementation with $\omega-3$ FAs to

Corresponding author: Dr. P.L. Selvais, University of Louvain Medical School and Saint-Luc Academic Hospital, UCL DIAB 5474, avenue Hippocrate 54, B-1200 Brussels, Belgium

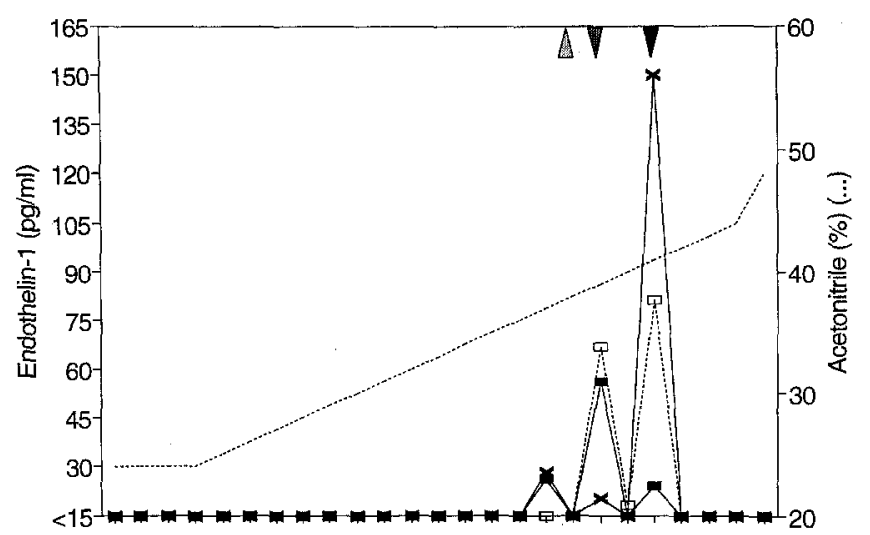

HPLC fractions (min)

Fig. 1. Characterization of serum ET-1 immunoreactivity by reverse-phase HPLC (24-44\% acetonitrile gradient on a $\mathrm{C}_{18}$ column, $1 \mathrm{ml} / \mathrm{min}$ ) in a non-microalbuminuric ( - ), a placebotreated microalbuminuric ( $¥)$, and a $\omega-3$ FAs-supplemented microalbuminuric diabetic subject $(\times)$, compared to synthetic oxidized ( $)$ and mature ET-1 ( $\mathbf{V})$ and big ET-1 ( $)$

microalbuminuric IDDM patients. This could represent either higher tissue levels of ET-1, or increased access of tissue ET-1 into the vascular compartment. By contrast, - angiotensin II plasma immunoreactivity is unaffected by $\omega-3$ FAs supplementation. Further investigation of the long-term effects of $\omega-3$ FAs-enriched diets on vasoactive peptides such as ET-1 is warranted in view of their increasing use in various conditions, including diabetic angiopathy.

We thank A. De Baets and F. Van linden for technical assistance.

Yours sincerely

P. L. Selvais, J. M. Ketelslegers, M. Buysschaert, M. P. Hermans

\section{References}

1. Takahashi K, Ghatei MA, Lam HC, O`Halloran DJ, Bloom SR (1990) Elevated plasma endothelin in patients with diabetes mellitus. Diabetologia 33: 306-310

2. Vermes I, Spooren PFMJ, Kalsbeek-Batenburg EM, Haanen C (1993) In addition to von Willebrand factor and urinary albumin excretion, plasma endothelin is an indicator of endothelial dysfunction in diabetes mellitus. Diabetologia 36: $472-473$

3. Malasanos TH, Stacpoole PW (1991) Biological effects of omega-3 fatty acids in diabetes mellitus. Diabetes Care 14: $1160-1179$

4. Colin I, Berbinschi A, Denef JF, Ketelslegers JM (1992) Detection and identification of endothelin- 1 immunoreactivity in rat and porcine thyroid follicular cells. Endocrinology 130: $544-546$

5. Collier A, Leach JP, McLellan A, Jardine A, Morton J, Small M (1992) Plasma endothelinlike immunoreactivity levels in IDDM patients with microalbuminuria. Diabetes Care 15: $1038-1040$ 